\title{
Os Limites e Contradições da Educação Bilíngue para Estudantes Surdos ${ }^{1}$
}

\author{
The Limits and Contradictions of Bilingual Education for Deaf Students
}

\author{
Nelson Dias ${ }^{\mathrm{a}^{*}}$; Alexandra Ayach Anache ${ }^{\mathrm{b}}$; Ruberval Franco Maciel ${ }^{\mathrm{c}}$ \\ ${ }^{a}$ Universidade Federal de Mato Grosso do Sul, Programa de Pós-Graduação Ensino de Ciências MS, Brasil. \\ bUniversidade Federal de Mato Grosso do Sul, Programa de Pós-Graduação em Psicologia. MS, Brasil \\ 'Universidade Estadual de Mato Grosso do Sul, Programa de Pós-Graduação em Letras. MS, Brasil. \\ *E-mail: nelsonufms@hotmail.com
}

\begin{abstract}
Resumo
O objetivo desse artigo é discutir e problematizar a perspectiva da educação bilíngue dos estudantes surdos, indicando características monolíngues presentes nessa abordagem. Para tanto, relacionam-se, na introdução, questões sobre os limites e desafios nos processos educativos desses estudantes. A análise está dividida em três eixos: Orientação monolíngue, contradições na educação bilíngues e, translinguagem como possibilidades. Para fundamentar a discussão buscou-se problematizar aspectos históricos que reforçaram este paradigma ainda presente hoje na educação. Os resultados apresentam várias contradições entre a legislação linguística e os documentos de políticas públicas que orientam a educação bilíngue dos estudantes surdos. A partir dessas contradições, ao longo do texto, discute-se sobre a inserção de uma orientação monolíngue na perspectiva do bilinguismo para esse público. No terceiro eixo de análise, levantam-se possibilidades de ampliar os conceitos de língua e linguagem na educação bilíngue sob a ótica da abordagem da translinguagem. Conclui-se que o bilinguismo na educação dos estudantes surdos não acontece como determina a legislação. Políticas públicas relacionadas a essa questão ainda favorecem a uma orientação que exclui o sujeito nos processos de ensino e aprendizagem. A perspectiva da translinguagem aponta para possibilidades emergentes que podem trazer um novo olhar na educação bilíngue dos estudantes surdos.
\end{abstract}

Palavras-chave: Translinguagem. Linguagem. Políticas Públicas.

\begin{abstract}
The aim of this article is to discuss and problematize the perspective of bilingual education for deaf students, indicating monolingual characteristics present in this approach. Therefore, questions about the limits and challenges in the educational processes of these students are listed in the introduction. The analysis is divided into three axes: Monolingual orientation, bilingual contradictions in education, and translanguaging as possibilities. To support the discussion, we sought to problematize historical aspects that reinforced this paradigm still present today in education. The results present several contradictions between the linguistic legislation and the public policy documents that guide the bilingual education of deaf students. Based on these contradictions, the text discusses the insertion of a monolingual orientation in the perspective of bilingualism for deaf. In the third axis of analysis, possibilities are raised for expanding the concepts of language and languaging in bilingual education from the perspective of the translanguaging approach. It is concluded that bilingualism in the education of deaf students does not happen as required by law. Public policies related to this issue still favor an orientation that excludes the subject in the teaching and learning processes. The perspective of translanguaging points to emerging possibilities that can bring a new look to the bilingual education of deaf students.
\end{abstract}

Keywords: Translanguaging. Language. Public Policy.

\section{Introdução}

A educação dos estudantes surdos tem passado, ao longo dos anos, por diversas metodologias e abordagens de ensino, entre elas, o oralismo, comunicação total e, atualmente, educação bilíngue. Nessa perspectiva, esses estudantes têm direito de serem instruídos pela Libras - Língua Brasileira de Sinais, sua língua materna, e, aprenderem a Língua Portuguesa, na modalidade escrita, como sua segunda língua. Quadros e Schimiedt (2006) reforçam a importância da Libras no desenvolvimento cognitivo das crianças surdas, uma vez que é por meio dessa língua que serão possíveis organizar o pensamento e ideias, bem como, promover interações com os colegas e professores no ambiente escolar.

No entanto, as dificuldades de aprendizagem desses estudantes ainda é realidade, conforme relatam Barros e Alves (2019) pensar em educação dos estudantes surdos requer conhecimento da especificidade cultural e linguística desse grupo. Quadros (2007) completa que a Libras possui modalidade visual-espacial articulada por meio das mãos, corpo e das expressões faciais. Desse modo, a educação bilíngue deve ser elaborada de forma que articule esses 1Pesquisa
tos ninculada com apoio da Universidade Federal de Mato Grosso do Sul. MS, Brasil 
elementos da língua, pois, esta, difere totalmente das línguas orais.

Apesar do bilinguismo ter ganhado cenário nas discussões sobre educação e estudantes surdos, ainda persistem métodos que se aproximam das abordagens oralistas e comunicação total, como é mencionado por Vieira e Molina (2018). Muitas atividades desenvolvidas nas escolas, em prol da educação bilíngue, na verdade sobrepõe a Língua Portuguesa sob a Libras, prejudicando o desenvolvimento da linguagem desse público. Essas autoras apontam que mudanças nas nomenclaturas, dessas perspectivas, não necessariamente implicam em mudanças conceituais.

Nessa ótica, uma abordagem que desconsidera a língua dos estudantes surdos no processo de aprendizagem leva a sérias consequências, na aquisição de uma segunda língua, sobretudo àquele em que se aprende na modalidade escrita. A Libras possui função primordial nessa aprendizagem, pois ocupará o lugar de mediador no processo de significação vivenciado pelo surdo, incluindo os significados adquiridos pela linguagem escrita. A escola, lugar de aprendizagem formal da língua escrita, ainda está pautada em uma perspectiva monolíngue e desconsidera a condição bilíngue dos estudantes surdos (SOUZA, 2019).

Grande parte dos estudantes surdos enfrentam dificuldades de aquisição da segunda língua. Moret e Rodrigues (2019) complementam que muitos progridem nos anos escolares sem mesmo terem conhecimento da Língua Portuguesa escrita. Para essas autoras, os alunos, possuem conhecimento dos conteúdos na Libras, entretanto, são prejudicados durante as atividades, uma vez que, os instrumentos utilizados nas avaliações priorizam apenas a linguagem escrita e desconsideram os sentidos produzidos em outra língua.

Libras e Língua Portuguesa deveriam estar articuladas no processo de ensino-aprendizagem dos estudantes surdos, no entanto, ficam isoladas no mesmo espaço da sala de aula. Lodi (2013) explica que a educação bilíngue ficou entendida apenas como a inserção do intérprete. O desdobramento dessa compreensão criou dois ambientes monolíngues nas aulas, que não contribui para a construção do conhecimento e nem para aquisição linguística.

As políticas públicas que versam sobre a educação dos estudantes surdos deixam a entender que a Libras não é privilegiada nesse processo, mas sim a Língua Portuguesa. A perspectiva bilíngue que deveria ser pautada na pluralidade está mais relacionada ao paradigma que orienta para uma única língua, uma identidade e uma cultura. Por esse motivo, nosso objetivo, nesse artigo, é discutir e problematizar a perspectiva da educação bilíngue dos estudantes surdos, indicando características monolíngues presentes nessa abordagem. Após, apresentaremos possibilidades de ampliar a compreensão sobre língua, linguagem e processos de produção de sentido em uma proposta emergente nas discussões sobre essa temática - a translinguagem.

\section{Desenvolvimento}

\subsection{Metodologia}

O presente estudo foi desenvolvido por meio de um levantamento bibliográfico. Segundo Gil (2008) esse tipo de pesquisa é elaborada a partir de estudos já realizados constituído de artigos e livros. Nesse sentido, foram selecionamos obras que problematizam a educação bilíngue como, Garcia, (2009), Canagarajah (2013, 2017), Li Wei e Garcia (2017), Vogel e Garcia (2017), Li Wei (2017), Blommaert (2010), Rocha e Maciel (2019, 2020). Para discutir sobre política linguística e educação dos estudantes surdos buscamos em Moreira e Fernandes (2009, 2014), Lodi (2013), Karnopp (2015), Quadros (1997, 2015), Kendrick e Cruz (2018), Andrade e Soares (2019) levantar questões e limites sobre a educação bilíngue dos estudantes surdos.

Os resultados e discussões desse artigo foram divididos em 3 eixos:

- Orientação monolíngue: análise relacionada ao percurso histórico e aspectos fundantes da orientação monolíngue.

- Contradições da educação bilíngue para estudantes surdos Relacionamos o documento de Política Nacional de Educação Especial com o decreto 5625/05, apontando suas contradições e como algumas práticas mais se relacionam com educação monolíngue;

- Translinguagens e possibilidades - A partir dos estudos levantados, discutimos a translinguagem como possibilidade aos limites apresentados da educação bilíngue para estudantes surdos.

\subsection{Discussão}

\subsubsection{Orientação monolíngue}

A educação bilíngue é a abordagem que está sendo utilizada como forma de instrução para os estudantes surdos na educação básica. Entretanto, como mencionamos na introdução desse texto, essa abordagem que poderia contemplar as duas línguas, Libras e Língua Portuguesa, as isola e não promove aprendizagem satisfatória. Karnopp (2015) explica que essa diferença está relacionada à dominação cultural que existe entre os ouvintes e surdos, ocasionando a prevalência de uma língua sob a outra. Nessa perspectiva, ainda é possível observar questões que colocam em dúvida a validade linguística da Libras no âmbito da sociedade. Para Gesser (2009) as discussões sobre línguas de sinais, na década de 1960, conferiram o status linguístico dessa modalidade. No entanto, a autora salienta, que ainda se faz necessário reforçar o mesmo discurso "[...] para chegarmos à legitimação e ao reconhecimento, por parte da sociedade como um todo, que a língua de sinais $\underline{\boldsymbol{E}}$ uma língua" (GESSER, 2009, p. 9, grifos da autora). Vale salientar que línguas orais minoritárias também perpassam por questões semelhantes. Quadros (1997) afirma que línguas indígenas, por exemplo, sofrem desvalorização em relação àquelas que são majoritária. Frente a isso, compreendemos que essas relações possuem gênese mais 
profunda, construída em um processo histórico de dominação linguística e cultural, por conta de uma ideologia que se solidificou no século XVIII - orientação monolíngue.

Esse paradigma tem seus primórdios na ideologia iluminista, a ascensão da ciência empírica, industrialização e burocracia. Tal orientação parecia prometer eficiência, controle e transparência. Canagarajah (2013) explica que o Romantismo foi um movimento que reforçou essa perspectiva. Pensadores desse período enfatizavam, em seus textos, que a língua é a essência de um povo, e, por esse motivo, encarna o espírito mais íntimo e os valores da comunidade. Essa ideia fez com que seus usuários fossem considerados legítimos e outros que não as utilizavam, ilegítimos.

Nessa ótica, a construção de língua foi elaborada a partir de uma ideologia monolíngue, para que determinados grupos estabelecessem poder político. Garcia (2009) afirma que estados-nação criaram diversas iniciativas de estruturação sistemática da língua como, produções de gramáticas, enciclopédias e dicionários, buscando fortalecê-las e padronizá-las.

A disseminação da ideia sobre utilizar apenas uma língua visava fortalecer determinado território, bem como, criar uma comunidade homogênea. Nesse modelo, Canagarajah (2013) explica que se caso indivíduos de determinado estado-nação se mostrassem abertos e influenciados a falar mais de uma língua, estes não conseguiriam expressar o real espírito do seu grupo. O autor afirma que os mais notórios e expressivos eram aqueles que se fechavam apenas em suas comunidades, utilizando uma única língua.

A noção de um padrão linguístico permitiu que a diversidade e a pluralidade de línguas fossem suprimidas, a busca por esse modelo dominante "disseminou ou fortaleceu valores linguísticos, culturais e sociais tidos como unificadores e universais" (MONTE MOR, 2014, p.3). Para a autora, a visão sobre unicidade e padrões na comunicação entre pessoas monolíngues e monoculturais não favorecem grupos que possuem línguas diferentes.

Essa trajetória viabilizou a construção de hierarquização das línguas. Vogel e Garcia (2017) mencionam que, ao logo do século XX, modelos de educação bilíngue foram baseados em competências estáticas e padronizadas que remetem às características monolíngues dos estados-nação. Os estudos sobre educação bilíngue nessa ótica foram direcionados para dois tipos de aquisição, bilinguismo aditivo e subtrativo.

Harms e Blanc (2000) explicam que bilinguismo aditivo é o desenvolvimento de ambas as línguas bem como suas culturas. A aprendizagem de uma segunda língua - L2, não ameaça, de nenhuma forma, a substituição da língua materna da criança - L1. Entretanto, para Garcia (2009) esse tipo de abordagem sempre ocorreu em grupos de línguas de prestígios e em famílias da elite. A autora reforça, que esse tipo de bilinguismo ainda possui características voltadas para a norma monolíngue.

No bilinguismo subtrativo, as línguas competem entre si ao invés de se complementarem. Nessa perspectiva, a minoria linguística "rejeita seus próprios valores culturais em favor daqueles grupos com maior prestígio econômico e cultural" (HARMS; BLANC, 2000, p.100). Essa rejeição ocasiona a substituição da língua materna pela segunda língua.

$\mathrm{Na}$ educação básica, é fácil encontrar uma reprodução da homogeneidade, quando se trata de educação bilíngue. Para Monte Mór (2014) a escola tradicional prioriza um trabalho sobre padrões linguísticos, culturais e comportamentais da língua majoritária. Desse modo, conseguimos compreender porque trabalhos baseados, em nome de uma concepção bilíngue, apontam mais em direção ao monolinguismo, principalmente no caso dos estudantes surdos, como mencionamos na introdução desse trabalho.

Esse paradigma influenciou um dos acontecimentos marcantes na trajetória dos sujeitos surdos. O congresso internacional de educação das pessoas surdas, conhecido como Congresso de Milão, realizado no ano 1880, estabeleceu que a educação desses sujeitos seriam realizadas apenas pelo método oralista. Fernandes e Moreira (2014) apontam que essa decisão afetaria a história dos surdos pelos cem anos seguidos. Esses autores afirmam que nesse evento participaram, "dos 164 delegados presentes, representando a Itália (87 delegados), a França (53 delegados), a Inglaterra, a América, a Suécia, a Bélgica e a Alemanha, apenas dois eram surdos" (FERNANDES; MOREIRA, 2014, p.53), como a maior parte dos delegados eram ouvintes as decisões que afetariam a educação dos surdos foi decidida por aquelas que não são usuários da língua de sinais.

O Congresso de Milão é o símbolo de um período em que a educação de surdos passou a ser planejada e praticada por ouvintes, à revelia do que os próprios educadores surdos defendiam como princípio pedagógico básico: aprender com base na língua de sinais (FERNANDES; MOREIRA, 2014, p.53).

Importante também compreender, nesse processo, a situação política em que a Itália passava naquele momento. Este país, recentemente emancipado, precisava estabelecer uma identidade coesa, unificada política e linguisticamente, bem aos moldes da concepção de estado-nação que mencionamos nos parágrafos anteriores. Fernandes e Moreira (2014) chamam atenção para o fato de que logo após a emancipação do país (década de 1860) a Itália passava por diversas dificuldades de ordem social, política e econômica. Além disso, possuía uma população que se deparava com uma diversidade linguística que se comunicava em dialetos e continuava condenada ao analfabetismo, em oposição a minoria letrada que falava e escrevia a língua italiana (FERNANDES; MOREIRA, 2014). Em outras palavras, a Itália não poderia legitimar mais uma língua diferente, ainda mais uma cuja a modalidade divergia da oral.

Nesse contexto, Fernandes e Moreira (2014) afirmam que a eliminação da língua de sinais das escolas, foi justificada para diminuir o impacto das variedades linguísticas daquele 
momento, reforçando a ideia de um povo, uma língua, uma nação, e, obrigando também as crianças surdas a aprenderem oralizar a língua comum.

No Brasil o método oralista foi adotado a partir do ano de 1911, conforme relata Goldfeld (1997). Mesmo com o evidente fracasso, essa perspectiva perdurou por quase cem anos. Na década de 1970, a Comunicação Total ganha cenário na educação dos surdos com o objetivo de utilizar línguas de sinais combinada com oralidade, escrita, mímica e outros recursos. Essa filosofia educacional também não produziu resultados satisfatório, no entanto, a língua de sinais, passa a ter evidência, uma vez que anteriormente era totalmente proibida.

Desse modo, discussões sobre educação em uma perspectiva bilíngue, começam a ganhar forma e culminam em uma política linguística quando a Libras é "[...] reconhecida como meio legal de comunicação e expressão" (BRASIL, 2002, art. $1^{\circ}$ ). Vale salientar que apenas no ano de 2005, com a criação do decreto 5626, passam a ser regulamentadas as formas de acesso e disseminação dessa língua nos ambientes escolares, bem como, diretrizes para formação profissional de professores e tradutores/intérpretes de Libras.

Nesse sentido, não abordaremos detalhes das concepções oralista e comunicação total, pois o foco desse estudo relaciona-se com políticas linguísticas e suas contradições na educação bilíngue, apontando quais são suas aproximações com a orientação monolíngue.

\subsubsection{Contradições da Educação bilíngue para estudantes surdos}

As políticas públicas voltadas para a educação bilíngue dos surdos, são frutos de movimentos de luta realizadas por comunidades surdas brasileiras. Mesmo que um dos marcos da histórico desse grupo inicie com a inauguração do Instituto para meninos surdos, no Rio de janeiro em 1857, esses movimentos só ganharam força na década de 1990. Fernandes e Moreira (2014) explicam que nesse período iniciavamse as discussões sobre legitimidade das línguas de sinais, educação bilíngue, estudos sobre cultura e identidade, dentre outros assuntos que causariam impacto na organização de um a educação bilíngue no Brasil. Nesse sentido, Kendrick e Cruz (2018) apontam que os movimentos de lutas dessas comunidades, buscam viabilizar acesso à Libras inclusive como meio de instrução.

As construções dessas políticas, são sem sombra de dúvidas, grandes conquistas. No entanto, quando as analisamos, percebemos que os primeiros documentos orientadores, estão "pautadas em paradigma contraditório, ora os tratando como 'deficientes' ora reconhecendo-os como grupo cultural” (FERNANDES; MOREIRA, 2009, p. 228). Para essas autoras, a concepção de educação especial, nesse primeiro período, defendia a inclusão dos estudantes surdos em escolas regulares. Entretanto, ainda privilegiavam um cunho terapêutico voltado para uma orientação monolíngue em prol da aquisição da oralidade. Essa ideologia reforça a não utilização da língua de sinais e traz uma ideia de reabilitação do sujeito pela fala. Excluindo-os de todo processo de construção de conhecimento e das possibilidades de interrelações social. A Libras não era inserida como protagonista no processo de ensino-aprendizagem dos estudantes surdos. Para Fernandes e Moreira (2009) tratar a língua dessa forma é o mesmo que categorizar os surdos como "deficientes" da linguagem. No entanto, essas autoras salientam que contrário a esse pensamento, mobilizou-se um movimento crescente organizado por surdos que pressionou o Estado para que a Libras tivesse mais visibilidade nos espaços sociais. Kendrick e Cruz (2018) explicam que esses movimentos buscavam ser reconhecidos não como público da educação especial, mas como um grupo com identidade cultural que possui uma língua diferente. Fernandes e Moreira (2009) reforçam que a educação bilíngue não é um método e nem uma nova educação, mas sim, apenas uma forma de garantir acesso e permanência nos espaços escolares e em outros espaços sociais.

Ao comparamos o que está escrita na letra da Lei com os documentos oficiais que orientam as práticas pedagógicas, percebemos incoerências sobre o que deveria de fato ser aplicado. Lodi (2013) explica que no Decreto Federal 5626/05 a Libras assume papel central nos processos de ensino e aprendizagem. No entanto, no documento que a autora analisou, "Política Nacional de Educação Especial", não fica claro qual língua deva ser usada pelos professores nas salas de aula inclusivas. Assim, a Libras que deveria ocupar protagonismo na produção de conhecimento perde espaço para a língua majoritária que sempre ocupou lugar de destaque nas ações pedagógicas do professor.

Em relação à política presente no "Atendimento Educacional Especializado -AEE", Moreira e Fernandes (2014) tecem críticas no que diz respeito às orientações para a educação especial na perspectiva inclusiva. As autoras afirmam que, neste documento, a Libras é considerada apenas como um recurso. A língua dos estudantes surdos passa a servir à orientação monolíngue baseada em um bilinguismo subtrativo, como mencionamos na seção anterior. Dessa forma, aos poucos, a Libras é assimilada pela Língua Portuguesa, não deixando espaço para que estudantes surdos aprendam àquela que foi garantida legalmente como meio de expressão e comunicação dessa comunidade.

Essa característica recursiva para aprendizagem da Língua Portuguesa também é relatado por Lodi (2013) ao mencionar que a Libras adquire, no texto da Política de Educação Especial, caráter instrumental, distanciando-se de seu status linguístico, que justifica a previsão de que o AEE ocorra em língua portuguesa, oral e escrita, e em Libras. Dessa forma, sem aprendizagem da primeira língua, são negados os direitos desses que por anos passaram por abordagens que não respeitavam sua identidade e cultura. Nesse primeiro período de educação bilíngue, essa perspectiva mais se aproxima do monolinguismo. De um lado enfatizando a aprendizagem 
da oralidade, em uma concepção de reabilitação. De outro lado, reforçando apenas a habilidade da aprendizagem da linguagem escrita, utilizando para isso a Libras como suporte instrumental.

Sem considerar a língua de sinais dos estudantes, a aprendizagem da escrita também ficará comprometida. Andrade e Soares (2019, p.60) concordam que "a apropriação da modalidade escrita da língua oficial do seu país pelos surdos configura-se como outro caminho para emancipação política e social desses sujeitos". Entretanto, essas autoras salientam que a língua natural dos sujeitos surdos é de modalidade visual-espacial. Nesse sentido, não levar em consideração essa característica, dificulta a aprendizagem de uma segunda língua em que a modalidade difere da sua.

Como explicar as diferenças e contradições presente nos documentos oficiais quando comparadas à legislação de política linguística para estudantes surdos? Mainardes (2006) explica que na dinâmica das políticas educacionais, existem ciclos ou facetas que acabam tendo expressões e impactos diferentes do esperado. Esse referido autor, apoia-se na teoria do ciclo de políticas desenvolvidas por Stephen Ball e Richard Bowe, para explicar as diferenças entre: o contexto da influência, da produção de texto e da prática.

O contexto de influência tem uma relação simbiótica, porém não evidente ou simples, com o segundo contexto, o contexto da produção de texto. Ao passo que o contexto de influência está frequentemente relacionado com interesses mais estreitos e ideologias dogmáticas, os textos políticos normalmente estão articulados com a linguagem do interesse público mais geral. Os textos políticos, portanto, representam a política. Essas representações podem tomar várias formas: textos legais oficiais e textos políticos, comentários formais ou informais sobre os textos oficiais, pronunciamentos oficiais, vídeos etc. Tais textos não são, necessariamente, internamente coerentes e claros, e podem também ser contraditórios. Eles podem usar os termos-chave de modo diverso. A política não é feita e finalizada no momento legislativo e os textos precisam ser lidos com relação ao tempo e ao local específico de sua produção (MAINARDES, 2006, p.52).

Dessa forma, é possível entender que mesmo estando presentes na lei, aspectos que precisariam ser aplicados, estes sofrem processos interpretativos que na verdade são resultados de disputas e acordos de grupos de interesse. Essa é uma tentativa de controlar suas representações políticas, no caso em questão, controlar a relação de poder que existe entre língua oral e língua de sinais reforçando assim a orientação monolíngue.

Quando lemos o art. $1^{\circ}$ da lei 10436/02 que oficializa a Libras percebemos que ela é apresentada como um meio legal de comunicação e expressão e não como uma das línguas oficiais do Brasil. Nesse sentido, políticas públicas serão construídas, a partir da compreensão de que a Libras seja apenas instrumentalização para a Língua Portuguesa, uma vez que essa última não pode ser substituída em sua modalidade escrita, como previsto legalmente. Andrade e Soares (2019) afirmam no que no decreto $5626 / 05$ é previsto a disciplina de Libras como componente curricular na educação básica, assim, tanto os surdos, quanto os ouvintes, partilhariam de ambas as línguas. No entanto, como isso ainda não é possível por questões econômicas e ideológicas, os surdos continuam sendo estrangeiros em seu país. Os esforços de implementação das políticas devem acontecer para que cidadãos surdos saiam da situação de opressão linguística e social.

Tomando a análise que Lodi (2013) e Fernandez e Moreira $(2009$; 2014) fizeram sobre os documentos que mencionamos nos parágrafos anteriores, podemos dizer que estes são resultados do "contexto da prática", termo utilizado por Mainardes (2006, p.53), pois “é onde a política está sujeita à interpretação e onde a política produz efeitos e consequências que podem representar mudanças e transformações significativas na política original". O autor ainda salienta, que nesse processo apenas algumas vozes são ouvidas e dadas como legítimas.

Os reflexos dessas contradições e disparidades presentes nos documentos oficiais geram, na visão de Fernandes e Moreira (2009), um cenário de extrema polêmica em "estudantes surdos sofrem as consequências desse antagonismo nos processos adotados nas escolas, concursos públicos e vestibulares, entre outros processos seletivos" (FERNANDES; MOREIRA, 2009, p.229). Outra consequência existente relaciona-se com a formação dos profissionais que atuam com estudantes surdos, garantida no decreto 5626/05. Na legislação, o perfil dos professores prevê formação específica para o ensino da Língua Portuguesa como segunda língua. No entanto, Lodi (2013) afirma que os documentos norteadores negligenciam essa característica não definindo, nem função, e, nem formação específica. Nesse sentido, a criação de cursos de formação na área da surdez não são priorizados.

Para Fernandes e Moreira (2009) existem dois modelos de educação bilíngue: modelo assimilacionista de submersão e modelo assimilacionista de transição. Esses modelos apresentados pelas autoras se aproximam muito do bilinguismo subtrativo que discutimos anteriormente. No primeiro incluise o aluno bilíngue em classe monolíngue, sem interação este abandona sua língua e migra para a Língua Portuguesa. No segundo modelo, o estudante bilíngue é incluído nas séries iniciais em uma classe cujo a língua de instrução é feita na sua língua materna, entretanto, esta será substituída gradativamente pela Língua Portuguesa. Na medida que o aluno vai avançando nos anos escolares, a língua materna é usada como instrumento, para a aprendizagem da língua dominante. Nesse sentido, os dois modelos são de assimilação da cultura e língua majoritária.

Muitos surdos que não concluíram a escolarização retornam para os ambientes escolares em turmas da EJA Educação de Jovens e Adultos. Andrade e Soares (2019) mencionam que essa modalidade de ensino, deve garantir oportunidades educacionais previstas na legislação, que 
priorize o ensino da Libras como a primeira língua, a Língua Portuguesa como a segunda, além do AEE. Para essas autoras, "a EJA, ofertada nas escolas e/ou centros de ensino com um modelo educacional que não contempla o cidadão surdo, nega o direito à educação previstos na Constituição (ANDRADE; SOARES, 2019, p.61). Nesse sentido, as autoras indicam, que apenas oportunizar a presença do tradutor/intérprete de Libras no espaço da sala de aula, não garante a legitimidade do processo, mas devem ser garantidas experiências que acolham os estudantes para que se sintam parte do lugar.

É possível observar a fragilidade do sistema de educação em atender as diretrizes legais, dentro de uma concepção bilíngue. Os documentos norteadores são contraditórios e apontam mais em direção à uma orientação monolíngue, como verificamos ao longo desse texto. Kendrick e Cruz (2019) enfatizam que os movimentos de luta da comunidade surda estão atentos a essas divergências. Para esses autores, as reivindicações apontam a educação bilíngue como necessária, mas a fragilidade como a inclusão escolar do surdo tem acontecido no Brasil compromete o sucesso da proposta, nesse espaço. A presença da Libras não tem ganhado seu papel protagonista dentro dos espaços da educação formal. Pelo contrário, as políticas as instrumentalizam para a aprendizagem da língua escrita, como a única forma aceita na sociedade ouvinte.

Crianças e jovens surdos deveriam ter uma educação que permitissem experiências linguísticas e culturais. Fernandes e Moreira (2014) enfatizam que os espaços escolares deveriam viabilizar uso e a disseminação da Libras, principalmente nas primeiras séries do ensino fundamental. Essas são questões podem nortear e viabilizar o acesso e permanência dos estudantes surdos no ambiente escolar, onde a Libras tenha o mesmo valor linguístico no espaço da sala de aula.

\subsubsection{Translinguagem e suas possibilidades na educação bilíngue dos estudantes surdos}

Translinguagem é uma perspectiva que traz uma noção mais ampliada sobre linguagem. Canagarajah (2017) explica que as pesquisas sobre essa temática têm se mostrado amplamente diversificada. $\mathrm{O}$ autor indica quatro macro eixos de abordagem relacionados à ela. $\mathrm{O}$ primeiro discute sobre a interação entre as línguas, o segundo está vinculado com a linguagem para além dos recursos verbais, o terceiro envolve características que transcendem texto/contexto no espaço-tempo, e, o último são as estruturas sociais e modificações nas relações de poder. Nosso foco de discussão, nesse artigo, explora apenas dois aspectos do primeiro eixo, linguagem móvel e transgressão da língua, problematizando as possibilidades de educação bilíngue com estudantes surdos.

A translinguagem é considerada uma abordagem que vem quebrar com os paradigmas que compreendem a linguagem como fixa. Garcia (2009) explica que a globalização, a tecnologia, comunicação em rede e migração de populações, trouxeram outras formas de compreender a interação entre a diversidade linguística. Para essa autora, não podemos mais, no século XXI, manter a educação bilíngue pautada na unicidade estrutural da língua, conforme discutimos na seção anterior. Nessa perspectiva, a educação dos estudantes surdos, a Libras ganha espaço na sala de aula, pois esta faz parte dessa diversidade no ambiente educacional. Trabalhar apenas com as normas, como o bilinguismo tradicional, fez com que a língua de sinais, ou, ficasse isolada apenas com os pares surdos e intérpretes, ou, fosse utilizada apenas como suporte instrumental.

Dentro de um contexto de mobilidade linguística, estamos em constante contato com outras línguas, por diversos meios, como músicas, filmes, textos, redes sociais, entre outras plataformas. Então, por que não compreendemos esse movimento como um recurso móvel da língua? Suresh Canagarajah em entrevista para Rocha e Maciel (2020) explica que ao pensarmos na concepção de língua por um caminho da linguística tradicional, enxergamos apenas a língua com estrutura estática e hegemonica. Dessa forma, turmas com estudantes surdos, ao concebermos apenas a norma, não validamos outras formas de linguagens que podem produzir sentido durante as aulas, são priorizadas apenas a modalidade escrita e oralidade da língua majoritária. Em uma ótica pela translinguagem, as linguagens visuais e outras semioses possuem igual valor dos outros recursos mencionados anteriormente. $\mathrm{O}$ professor ao realizar seu planejamento, precisa indicar quais linguagens utilizará para além da oralidade e escrita, de forma a contemplar o acesso e particiação dos estudantes surdos em sua aula.

Nesse mesmo viés, Canagarajah (2013) traz contribuições importantes sobre a prática da linguagem entre pessoas bilíngue. Esse autor explica que em situações reais, as interações desses sujeitos ocorrem de forma dinâmica com estratégias de produção de sentido que envolvem diversos recursos semióticos na comunicação. $\mathrm{O}$ envolvimento entre a Libras e a Língua Portuguesa, por meio dessa abordagem, ganham novas configurações no processo de aprendizagem e produção do conhecimento. Estudantes surdos ao participarem das aulas com a liberdade de utilizarem sua língua na explicação de conteúdo, apresentação de trabalhos, na interação com colegas ouvintes, ampliam as possibilidades comunicação e aprendizagem. Dessa forma, os estudantes ouvintes terão acesso aos sentidos produzidos na Libras pelos estudantes surdos, uma vez que, em uma perspectiva estruturalista não seriam possíveis.

O bilinguismo, em uma perspectiva translíngue, visa contemplar a complexidade de ambas as línguas. Para Garcia (2009), essa proposta de educação bilíngue, não pode ser nem subtrativa e nem aditivo, mas sim dinâmico. Essa autora argumenta que sujeitos bilíngues utilizam todo o repertório linguístico na negociação de sentido. As línguas, não formam compartimentos distintos e isoladas, mas transitam em um sistema amplo e complexo. Dessa maneira, os estudantes surdos ao transitarem com a Libras nas aulas, 
utilizarão a Língua Portuguesa na modalidade escrita para ampliar os sentidos que serão construídos nesse dinamismo. Ao utilizarem a escrita em atividades e avaliações, o farão apoiados na língua de sinais, não como instrumento, mas sim como eixo central da aprendizagem, com possibilidades de explicarem também na sua língua, pois estão em processo de aquisição da escrita.

Importante frisar que nas interações entre pessoas de diferentes línguas dificilmente estas terão o mesmo nível linguístico. De acordo com Fernandes e Moreira (2014) cerca de 95\% dos estudantes surdos nascem em lares de pais ouvintes. $\mathrm{O}$ acesso/contato à língua de sinais acontece muitas vezes de forma tardia. Dessa forma, a aprendizagem, tanto da Libras, quanto da Língua Portuguesa na modalidade escrita, acontecem ao mesmo tempo. Isso não significa, que esse público, tenha menos repertório linguístico. Blommaert (2010) explica que ninguém conhece tudo de uma língua. Isso inclui nossas línguas maternas e outras línguas que vamos adquirindo ao longo da vida. Para esse autor, não há nada de errado em ter competência linguística parcial, pois, temos a disposição várias competências e habilidades para usar diversos gêneros e modalidades específicos na comunicação. Essa diversidade envolve nossa trajetória educacional, conhecimento regional e identidade social.

Pode-se inferir que são nas práticas comunicativas que são construídos os repertórios. Nesse sentido, apostar em uma abordagem que valorize as duas línguas no contexto da sala de aula possibilita a ampliação desse repertório. Blommaert (2010) afirma essa constituição é realizada a partir de um conjunto complexo de recursos individuais de pessoas reais, organizadas em um espaço sociocultural, histórico e político. Para este autor, à medida que as pessoas absorvem os recursos semióticos, esses se tornam disponíveis para a necessidade e utilidade social entre interlocutores específicos.

Outra questão a ser inserida nesse debate, é a transgressão da língua frente orientação monolíngue da Língua Portuguesa sobre a Libras. Para Li Wei (2017) o pensamento das pessoas bilingues não isolam as línguas. O autor explica que pensar querer um uso integrado das variedades de recursos semióticos, linguísticos e modais. Dessa maneira, conceber a linguagem em favor de apenas uma língua retrocedemos ao senso convencional de fala e escrita como a forma hegemônica de linguagem, desconsiderando assim, todas as outras formas de produzir sentido que possam emergir da relação. Estudantes surdos possuem repertórios que podem ser compartilhados com seus pares ouvintes, pois a Língua Portuguesa não é a única. A Libras traz uma variedade de recursos linguísticos e modais que podem enriquecer a aprendizagem de ambos estudantes.

Além de colocar a Libras em destaque na produção de conhecimento, organizamos um ambiente mais justo para os estudantes surdos. Li Wei e Garcia (2017) afirmam que partir de um olhar translíngue, as pessoas tornam-se visíveis. Para esses autores, as histórias desses sujeitos ganham visibilidade e protagonismo. Translinguar é transformar a paisagem para criar um espaço social, histórico, onde pessoas multilíngues e bilíngues possam compartilhar, em diferentes dimensões, suas experiencias e histórias de vida.

Para que possamos compreender o uso da linguagem nas práticas sociais, precisamos pensar para além do que está posto. O prefixo "trans" infere em uma prática bilíngue dinâmica onde as pessoas possam "transitar entre as línguas dentro de um sistema único e integrado" (REIS; GRANDE, 2017, p.132). Dessa forma, não podemos negar a identidade bilíngue dos estudantes surdos. Separar as línguas ou isolálas no processo de ensino, não contribui no desenvolvimento desses estudantes. Pelo contrário, ao não considerar todo o repertório linguístico do sujeito, estamos negando sua constituição bilíngue e reforçando a assimilação de uma língua pela outra.

A educação bilíngue, na perspectiva translíngue "se refere à desestabilização de normas e ideologias predominantemente centralizadoras e opressoras em uma diversidade de aspectos" (ROCHA; MACIEL, 2019, p.120). Na educação dos estudantes surdos, não levar essas características em consideração, mantém a reprodução de práticas da linguagem, em nome de um bilinguismo, que ainda são voltadas à orientação monolíngue. Tal concepção, insere os surdos como sujeitos "deficientes" da linguagem, e atribui à Libras, caráter instrumental para aprendizagem da Língua Portuguesa, como discutimos anteriormente.

Transgredir a concepção de língua vai além de só compreender a translinguagem como mais um neologismo. Li Wei e Garcia (2017) afirmam que o 'trans' pressupõe não só a prática da linguagem, mas também, abrem possibilidades para aliá-las à educação analisando as relações e estruturas sociais, a cognição, aprendizagem e sociabilidade humana. Nesse sentido, o 'trans' busca compreender o sujeito na sua totalidade, em um espaço que possa ser participativo e protagonista de seu discurso.

\section{Conclusão}

Educação bilíngue está pautada em uma ideologia que reforça o paradigma da orientação monolíngue, construída ao longo dos séculos, movida pelo lema: um estado, uma língua, uma nação. Tal perspectiva move-se em prol de um bilinguismo aditivo e subtrativo. Estes, enfatizam concepção estruturais e normativas das línguas, e, não abrem espaço para outras linguagens que possam emergir das interações comunicacionais.

Alegislação linguística construída no Brasil sobre educação bilíngue dos estudantes surdos, são frutos de movimento de luta das comunidades surdas. No entanto, mostram-se contraditórias quando confrontadas com os documentos que orientam as práticas educacionais. A Libras assume, nas políticas públicas, caráter instrumental na aprendizagem da Língua Portuguesa, perdendo seu status linguístico. O bilinguismo, nessa abordagem, tem características subtrativa, 
uma vez que a língua de sinais, não possui valorização e nem protagonismo nos processos educacionais.

A translinguagem aponta como possibilidade na elaboração de uma abordagem plural na educação bilíngue dos estudantes surdos. Essa perspectiva compreende o bilinguismo de forma dinâmica e aberta. As línguas podem transitar na negociação de sentidos, Libras e Língua Portuguesa passam a compor um repertório amplo e complexo, e, são valorizadas outras linguagens que possam emergir da interação. Essa abordagem, pode ser vista como uma forma de transgressão à hegemonia e dominação da língua majoritária, legitimando outras formas de construir sentido, que não seriam possíveis em uma abordagem estruturalista.

\section{Referências}

ANDRADE, P.S.L; SOARES, C.V.C.O. Considerações em torno da política linguística da Libras e da educação bilíngue libras/ língua portuguesa na educação de jovens e adultos surdos. Rev. Educ. Linguagens, v.8, n.14, 2019. Disponível em: http:/www. fecilcam.br/revista/index.php/educacaoelinguagens/article/ viewFile/1861/1223. Acesso em 20/05/2020.

BARROS, H.A; ALVES, F.R.V. As principais abordagens de ensino para o surdo: e a valorização da cultura dos surdos. Res., Soc. Dev, v.8, n.8, p.e38881231, 2019. doi: http://dx.doi. org/10.33448/rsd-v8i8.1231.

BLOMMAERT, J. The Sociolinguistics of Globalization. Cambridge: University Press, 2010.

BRASIL. Lei n. 10.436, de 24 de abril de 2002. Dispõe sobre a Língua Brasileira de Sinais - LIBRAS e dá outras providências. Diário Oficial[da] República Federativa do Brasil, Brasília, DF, 2002

BRASIL. Decreto de Lei No 5626 de 22 de Dezembro de 2005. Regulamenta a Lei no 10.436, de 24 de abril de 2002, que dispõe sobre a Língua Brasileira de Sinais - Libras, e o art. 18 da Lei no 10.098, de 19 de dezembro de 2000. Diário Oficial[da] República Federativa do Brasil, Brasília, DF, 2005.

CANAGARAJAH, S. Translingual practice. New York: Routledge, 2013.

CANAGARAJAH, S. Translingual practice as spatial repertoires: expanding the paradigm beyond structuralist orientations. Applied Linguistics, v.39, n.1, p.31-54, 2018. doi: 10.1093/ applin/amx041.

FERNANDES, S.; MOREIRA, L.C. Políticas de educação bilíngue para surdos: o contexto brasileiro. Educ. Rev., n.2, p.5169, 2014. doi: https://doi.org/10.1590/0104-4060.37014.

FERNANDES, S.; MOREIRA, L.C. Desdobramentos político-pedagógicos do bilinguismo para surdos: reflexões e encaminhamentos. Educ. Especial, v.22, n.34, p.225-236, 2009. doi: http://dx.doi.org/10.5902/1984686X.

GARCIA, O. Bilingual education in the 21st century: a global perspective. Oxford: Wiley Blackwell, 2009.

GESSER, A. Libras? Que Língua é essa? Crenças e preconceitos em torno da língua de sinais e da realidade surda. São Paulo: Parábola Editorial, 2009.

GIL, A.C. Como elaborar projetos de pesquisa. São Paulo: Atlas, 2008.

GOLDFELD, M. A criança surda: linguagem e cognição numa perspectiva sócio-interacionista. São Paulo: Plexus, 1997.
HARMS, J.F; BLANC, M.H.A. Bilinguality and bilingualism. Cambridge University Press 2000.

KARNOPP, L.B. Práticas de leitura e escrita em escolas de surdos. In: FERNANDES, E. Surdez e bilinguismo. Porto Alegre: Mediação, 2015. p.65-79.

KENDRICK, D; CRUZ, G.C. Oficialização da Libras: movimento surdo e política linguística de resistência. Rev. Trama, v.14, n.32, p.1-14, 2018.

LI WEI. Translanguaging as a practical theory of language. Appl. Linguistics, v.39, n.1, p.9-30, 2018. doi: https://doi.org/10.1093/ applin/amx039.

LI WEI; GARCIA, O. From researching translanguaging to translanguaging research. In: KING, K. et al. Research methods in language and education. Encyclop. Language Educ., p.1-14, 2017. doi 10.1007/978-3-319-02329-8_16-1.

LODI, A.C.B. Educação bilíngue para surdos e inclusão segundo a Política Nacional de Educação Especial e o Decreto $\mathrm{n}^{\mathrm{o}}$ 5.626/05. Educ. Pesq., v.39, n.1, p.49-63, 2013. doi: https://doi. org/10.1590/S1517-97022013000100004.

MAINARDES, J. Abordagem do ciclo de políticas: uma contribuição para a análise de políticas educacionais. Educ. Soc., v.27, n.94, p.47-69, 2006. doi: https://doi.org/10.1590/S010173302006000100003.

MONTE MÓR, W. Convergência e diversidade no ensino de línguas: expandindo visões sobre a "diferença". Polifonia, v.21, n.29, p.234-253, 2014.

MORET, M.C.F.F.; RODRIGUES, J.G. A proposta bilíngue na educação de surdos: práticas pedagógicas no processo de alfabetização no município de colorado do oeste/Rondônia. Holos, v.35, n.2, e5933, 2019. doi: 10.15628/holos.2019.5933.

QUADROS, R.M. Educação de surdos: a aquisição da linguagem. Porto Alegre: Artes Médicas, 1997.

QUADROS, R.M. O tradutor interprete de Línguas de Sinais e Língua Portuguesa. Brasília: MEC, 2007.

QUADROS, R.M.; SCHIEDT, M.L.P. Idéias para ensinar português para alunos surdos. Brasília: MEC, 2006.

REIS, M.O; GRANDE, G.C. A translinguagem como ferramenta de aprendizagem e identidade na escrita acadêmica. Rev. Papéis, v.21, no 41, p.129-150, 2017.

ROCHA, C.H; MACIEL, R.F. Multimodalidade, letramentos e translinguagem: diálogos para a educação linguística contemporânea. In: SANTOS, L.I.S.; MACIEL, R.F. Formação e prática docente em Lingua Portuguesa e Literatura. Campinas: Pontes, 2019. p.117-144.

ROCHA, C.H.; MACIEL, R.F. Dialogues on translingual research and practice: weaving threads with Suresh Canagarajah 's views. Rev. $X$, v.15, n.1, p.7-31, 2020.

SOUZA, T.R.S. A expressão do sujeito surdo por meio da escrita em língua portuguesa. São Carlos: Universidade Federal de São Carlos-UFSCar, 2019.

VOGEL, S.; GARCIA, O. Translanguaging. In: NOBLIT, G.; MOLL, L. Oxford Research Encyclopedia of Education. Oxford: Oxford University Press, 2017. doi: 10.1093/ acrefore/9780190264093.013.181

VIEIRA, C.R; MOLINA, K.S.M. Prática pedagógica na educação de surdos: o entrelaçamento das abordagens no contexto escolar. Educ. Pesq., v.44, e179339, 2018. doi: http://dx.doi.org/10.1590/ S1678-4634201844179339. 